\title{
FAST NEUTRON RADIOGRAPHY FOR CLINICAL DIAGNOSIS
}

P. B. PARKS

M. BROWN
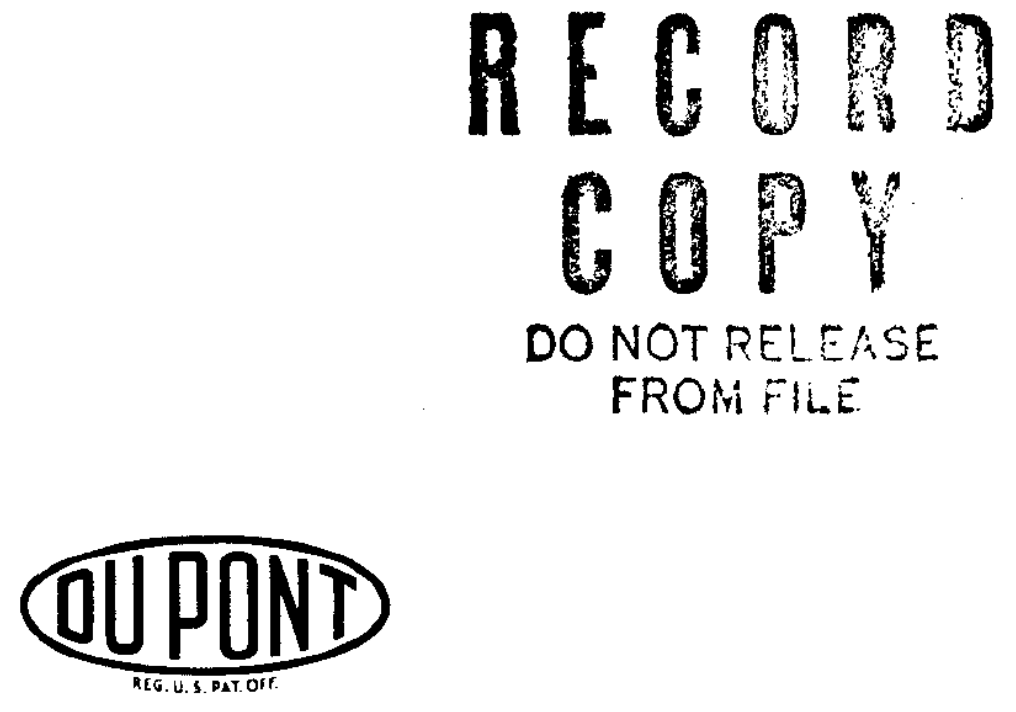

Savannah River Laboratory

Aiken, South Carolina 


\section{NOTICE}

This report was prepared as an account of work sponsored by the United States Government. Neither the United States nor the United States Atomic Energy Commission, nor any of their employees, nor any of their contractors, subcontractors, or their employees, makes any warranty, express or implied, or assumes any legal liability or responsibility for the accuracy, completeness or usefulness of any information, apparatus, product or process disclosed, or represents that its use would not infringe privately owned rights.

Printed in the United States of America

Available from

National Technical Information Service

U.S. Department of Commerce

Springfield, Virginia 22151

Price: Printed Copy $\$ 3.00$; Microfiche $\$ 0.65$ 


\author{
by \\ P. B. Parks \\ Experimental Physics Division \\ Savannah River Laboratory \\ and \\ M. Brown \\ Medical College of Georgia \\ Augusta, Georgia \\ Approved by \\ B. C. Rusche, Research Manager \\ Experimental Physics Division
}

September 1970

\author{
E. I. DU PONT DE NEMOURS \& COMPANY \\ SAVANNAH RIVER LABORATORY \\ AIKEN, S. C. 29801 \\ CONTRACT AT(07-2)-1 WITH THE \\ UNITED STATES ATOMIC ENERGY COMMISSION
}




\begin{abstract}
Fast neutron radiography was found to be impractical for medical diagnosis. Calculations showed that this type of radiography could be accomplished at acceptable radiation dose levels, but with practical sources and known detector systems, the calculated exposure times would be longer than acceptable to practicing radiologists.

Only ${ }^{252} \mathrm{Cf}$ and small ${ }^{3} \mathrm{H}(\mathrm{d}, \mathrm{n})$ accelerators were considered to be potentially useful sources for fast neutron radiography. Calculations showed that fat, muscle, and bone would have relatively little contrast against each other, but suggested that air pocket imaging might be useful, such as in lung radiography.

Proposed broad beam and transmission scanning imaging systems were evaluated in terms of $\boldsymbol{\gamma}$-ray and scattered neutron interference, and the clinical constraints of dose and exposure time. Known broad beam detection schemes that could minimize $\gamma$ interference from ${ }^{252} \mathrm{Cf}$ sources were too inefficient for the rapid imaging required in clinical situations. Moreover, scattered neutron interference could not be removed. Transmission scanning, which could minimize $\boldsymbol{\gamma}$-ray and scattered neutron backgrounds, was even slower and hence unacceptable.

Only ${ }^{3} \mathrm{H}(\mathrm{d}, \mathrm{n})$ broad beam radiography can be accomplished in exposure times within an order of magnitude of clinically acceptable limits. However, ${ }^{3} \mathrm{H}(\mathrm{d}, \mathrm{n})$ radiography was judged to have no advantage over existing roentgenographic techniques.
\end{abstract}




\section{CONTENTS}

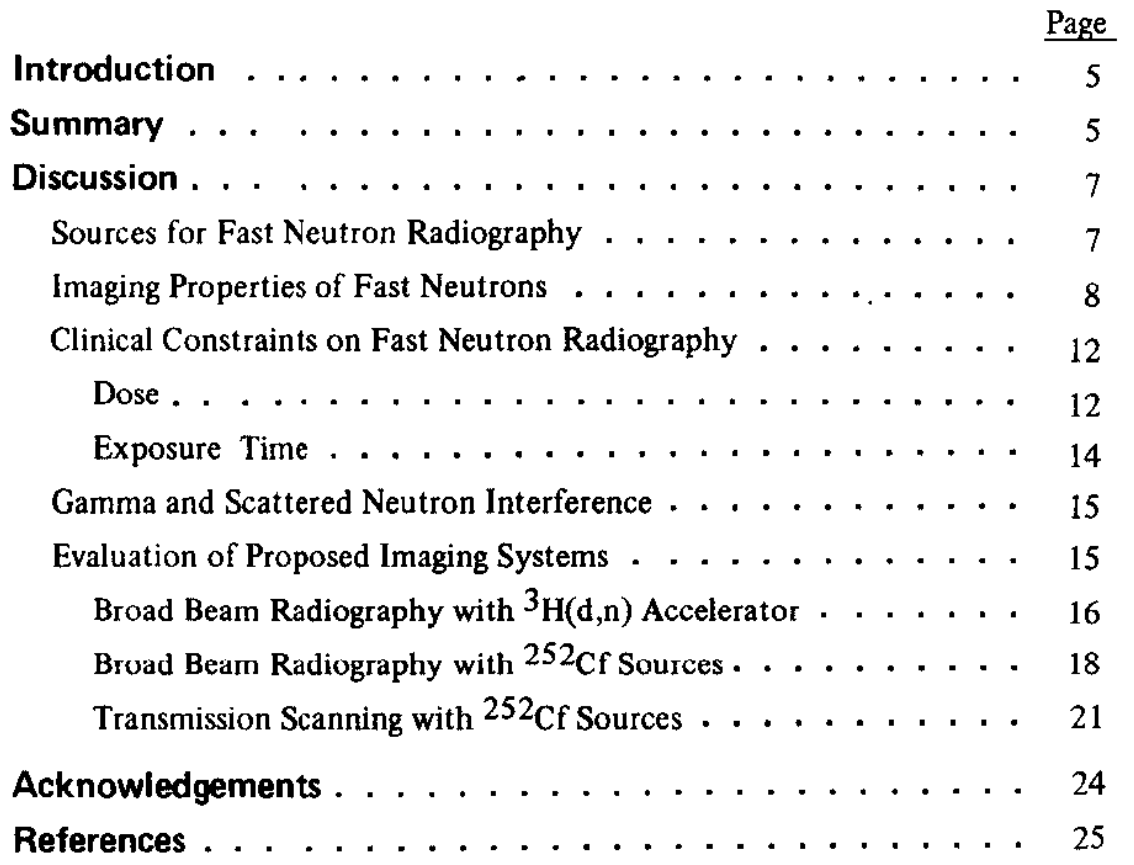




\section{LIST OF TABLES AND FIGURES}

Table $\quad \underline{\text { Page }}$

I Isotopic Neutron Sources and Cockcroft-Walton Accelerator. . . . 7

II Design Data for Transmission Scanning . . . . . . . . . . . . 23

\section{Fiqure}

1 Linear Attenuation Coefficients of Fast Neutrons in Various Human Tissues . . . . . . . . . . . . . . . 10

2 Contrast of Air, Bone, and Fat in Various Thicknesses of Muscle for ${ }^{252} \mathrm{Cf}$ Source Spectrum . . . . . . . . . . . . 11

3 Linear Attenuation Coefficients of the Elements for 60-kev $\mathrm{X}$-rays and for 2.3- and 14- Mev Neutrons . . . . . . . . 11

4 Comparison of the dose per unit fluence delivered to the surface of 30 -cm phantom by $60 \cdot \mathrm{kev} \mathrm{X}$-rays, $2.3-\mathrm{Mev}$ Neutrons and 14.7- Mev Neutrons . . . . . . . . . . . 13

5 Dose and Exposure Time for Imaging with a ${ }^{3} \mathrm{H}(\mathrm{d}, \mathrm{n})$ accelerator $\left(10^{11}\right.$ neutrons $\left./ \mathrm{sec}\right)$ and with a $100 \%$ Efficient Detector at $61 \mathrm{~cm}$ from the Source . . . . . . . . . . . 17

6 Comparison of 60-KVP X-ray, 2-Mev X-ray, and 14.7-Mev Neutron radiograph of Dog's Chest (Lateral Exposure) . . . . 18

7 Required Dose and Exposure Time for Broad Beam Imaging with a $100 \%$ Efficient Detector at $61 \mathrm{~cm}$ from a $100-\mathrm{mg}{ }^{252} \mathrm{Cf}$ Source . . . . . . . . . . . . . . . 19

8 Line Transmission Scanning Facility with Colinear Array of Scintillating Fibers 


\section{INTRODUCTION}

Fast neutron radiography, as a complementary technique to conventional roentgenography for the diagnosis of human disease, has been studied jointly by the Medical College of Georgia and the Savannah River Laboratory.

In almost all applications, neutron radiography has used thermal neutrons from a reactor source. ${ }^{1}$ Clinical applications of this technique, however, are severely restricted by the inability of slow neutrons to penetrate thick tissue specimens without delivering unreasonably large radiation doses. ${ }^{2-5}$ Slow neutron attenuation may be decreased somewhat if the tissues are deuterated by exposure to $\mathrm{D}_{2} \mathrm{O} .^{6}{ }^{7}$ The neutron linear attenuation coefficients of tissue, even at relatively high hydrogen-deuterium exchange levels, are still too large to permit slow neutron radiography of the thicker portions of the human anatomy.

At neutron energies greater than $100 \mathrm{kev}$, tissue attenuation coefficients decrease rapidly because the cross section of hydrogen decreases. Neutren attenuation coefficients of tissue between the energies of $200 \mathrm{kev}$ and $14 \mathrm{Mev}$ are similar to the X-ray coefficients in the energy range used in conventional roentgenography, $20 \mathrm{kev}$ to $150 \mathrm{kev}^{5}$ The similarity of tissue penetration by fast neutrons to that by conventional X-rays prompted a study of the characteristics of fast neutron radiography and its applicability to clinical diagnosis.

\section{SUMMARY}

Fast neutron radiography is not yet practical for medical diagnosis, as shown by consideration of :

- The properties of available or projected neutron sources.

- The image contrasts that are attainable by fast neutron radiography of biological media.

- The instrumentation problems associated with anticipated image interference from $\gamma$-rays and scattered neutrons.

A survey of potential sources for fast neutron radiography showed that ${ }^{252} \mathrm{Cf}$ isotopic sources and small deuteron accelerators with tritium targets have the highest ratio of neutron yield to source size. Small sources are necessary to obtain sharp images. 
Calculations of the maximum contrasts obtainable by fast neutron radiography suggested possible use for radiography of the lungs. Similarly, other naturally occurring and artificially produced gas pockets could be imaged, such as in pneumoencephalography. The calculations indicated that:

- Muscle would be indistinguishable from fat in radiographs taken with either ${ }^{252} \mathrm{Cf}$ or a ${ }^{3} \mathrm{H}(\mathrm{d}, \mathrm{n})$ accelerator.

- Bone would have no contrast against soft tissue with ${ }^{252} \mathrm{Cf}$, but a small bone contrast would exist in radiographs taken with the accelerator.

- Positive contrast agents, analogous to the organic iodides of conventional roentgenography, would be ineffective for fast neutron radiography.

Two types of imaging systems were considered for air pocket imaging: broad beam radiography, which is analogous to the conventional roentgenography, and narrow beam transmission scanning. Broad beam imaging can be compromised by two problems inherent to fast neutron radiography: interference from neutrons scattered within the specimen, and interference from superimposed contrasts caused by $\boldsymbol{\gamma}$-rays originating in the source (and to some extent from within the specimen). No solution to the scattered neutron interference problem was found for broad beam radiography with either ${ }^{252} \mathrm{Cf}$ or ${ }^{3} \mathrm{H}(\mathrm{d}, \mathrm{n})$ accelerators. The $\gamma$ content of the emissions from the ${ }^{3} \mathrm{H}(\mathrm{d}, \mathrm{n})$ accelerator was shown to be small. However, calculations showed that the image interference from the $\gamma$-rays of a ${ }^{252} \mathrm{Cf}$ source would be severe unless a detector insensitive to $\gamma$-rays could be devised.

A broad beam imaging system having the highest known efficiency for detecting fast neutrons consistent with an acceptable degree of $\gamma$ minimization was evaluated. Calculations showed that al though dose levels would be acceptable with ${ }^{252} \mathrm{Cf}$ broad beam radiography, the required exposure times with practical sources would be much too long.

Narrow beam transmission scanning was considered as a means of coping with both $\gamma$-ray and scattered neutron interference. Gamma sensitivity can be reduced without large neutron losses by conventional electronic biasing, and the narrow beam collimators would minimize the scattered neutron interference. Although dose levels would be acceptable for radiography with ${ }^{252} \mathrm{Cf}$ sources, working devices would require much development. Furthermore, the exposure times for air pocket imaging would be even longer than with broad beam systems and hence unacceptable.

With ${ }^{3} \mathrm{H}(\mathrm{d}, \mathrm{n})$ broad beam radiography, exposure times were calculated to be within an order of magnitude of clinically acceptable limits. However, experimental radiographs showed considerably less contrast sensitivity than that calculated. ${ }^{1} \mathrm{H}(\mathrm{n}, \gamma)$ production within the specimens and scattered neutron interference probably produced image compromising backgrounds. The ${ }^{3} \mathrm{H}(\mathrm{d}, \mathrm{n})$ radiographs were judged to have no clinical advantage over existing roentgenographic techniques. 


\section{DISCUSSION}

\section{SOURCES FOR FAST NEUTRON RADIOGRAPHY}

The emission rate of a nonreactor neutron source is usually so small that the source must be placed as close to the detector as possible (consistent with shielding and beam definition requirements). Therefore, the source dimension must also be small (less than $1 \mathrm{~cm}$ ) so that the neutron image of an object placed between the source and detector will be sharp.

Table I lists the yields and estimated volumes of several isotopic neutron sources, ${ }^{8}$ compared with the output and source diameter of a reasonably well-focused CockcroftWalton accelerator. Both ${ }^{252} \mathrm{Cf}$ and the ${ }^{3} \mathrm{H}(\mathrm{d}, \mathrm{n})$ accelerator exhibit the largest specific yields and the smallest source dimensions of known neutron sources. For this reason, only these two sources were considered potentially suitable for medical diagnosis by fast neutron radiography.

\section{TABLE |}

\section{ISOTOPIC NEUTRON SOURCES ${ }^{8}$ AND COCKCROFT-WALTON ACCELERATOR}

\begin{tabular}{|c|c|c|c|c|c|}
\hline Source & Type & $\begin{array}{l}\text { Average } \\
\text { Neutron } \\
\text { Energy }\end{array}$ & \begin{tabular}{l}
\multicolumn{1}{c}{ Yield, } \\
neutrons/ \\
(sec-Ci)
\end{tabular} & Half-Life & $\begin{array}{l}\text { Volume, } \\
\mathrm{cm}^{3}\end{array}$ \\
\hline${ }^{124} \mathrm{Sb}-\mathrm{Be}$ & $\gamma, \mathrm{n}$ & $24 \mathrm{kev}$ & $1.6 \times 10^{6}$ & 60 days & .200 \\
\hline${ }^{239} \mathrm{Pu} \cdot \mathrm{Be}$ & $a, \mathrm{n}$ & $4.5 \mathrm{Mev}$ & $2.0 \times 10^{6}$ & 24,400 years & ... \\
\hline $24{ }^{1} \mathrm{Am}-\mathrm{Be}$ & $a, n$ & $\sim 4 \mathrm{Mev}$ & $2.0 \times 10^{6}$ & 458 years & $2.2 \times 10^{4}$ \\
\hline $210 \mathrm{Po}-\mathrm{Be}$ & $a, n$ & $4.3 \mathrm{Mev}$ & $2.5 \times 10^{6}$ & 138 days & 200 \\
\hline${ }^{238} \mathrm{Pu}-\mathrm{Be}$ & $a, n$ & $\sim 4 \mathrm{Mev}$ & $2.8 \times 10^{6}$ & 89 years & 350 \\
\hline${ }^{244} \mathrm{Cm}-\mathrm{Be}$ & $a, \mathrm{n}$ & $\sim 4 \mathrm{Mev}$ & $3 \times 10^{6}$ & 18.1 years & 70 \\
\hline${ }^{242} \mathrm{Cm}-\mathrm{Be}$ & $a, n$ & $\sim 4 \mathrm{Mev}$ & $4 \times 10^{6}$ & 163 days & 2 \\
\hline${ }^{226} \mathrm{Ra}-\mathrm{Be}$ & $a, \mathrm{n}$ & $\sim 3.6 \mathrm{Mev}$ & $1.5 \times 10^{7}$ & 1620 years & -- \\
\hline \multirow[t]{2}{*}{${ }^{252} \mathrm{Cf}$} & $\begin{array}{l}\text { spontaneous } \\
\text { fission }\end{array}$ & $2.3 \mathrm{Mev}$ & $4.4 \times 10^{9}$ & 2.65 years & $<1$ \\
\hline & Type & $\begin{array}{l}\text { Average } \\
\text { Neutron } \\
\text { Energy }\end{array}$ & $\begin{array}{c}\text { Yield, } \\
\text { neutron/ } \\
\text { (sec-ma) }\end{array}$ & $\begin{array}{l}\text { Target } \\
\text { Half-Life } \\
\text { (unrotated) }\end{array}$ & $\begin{array}{l}\text { Accelerated } \\
\text { Beam Diameter } \\
\text { At Tarket }\end{array}$ \\
\hline \multirow[t]{2}{*}{$\begin{array}{l}\text { Typical } \\
\text { Cockcroft- } \\
\text { Walton } \\
\text { Accelerator } \\
(150 \mathrm{KV})\end{array}$} & ${ }^{3} \mathrm{H}(\mathrm{d}, \mathrm{n})$ & $14.7 \mathrm{Mev}$ & $1 \times 10^{11}$ & $\begin{array}{l}4 \text { hours at } \\
1 \mathrm{ma} \\
\text { continuous } \\
\text { current }\end{array}$ & $\sim 1 \mathrm{~cm}$ \\
\hline & ${ }^{2} \mathrm{H}(\mathrm{d}, \mathrm{n})$ & $\begin{array}{l}2.2- \\
2.8 \mathrm{Mev}\end{array}$ & $5 \times 10^{8}$ & $\cdots$ & $\sim 1 \mathrm{~cm}$ \\
\hline
\end{tabular}

a. Volume for $5 \times 10^{10}$ neutrons/sec 
The detailed radiation properties of ${ }^{252} \mathrm{Cf}$ are reviewed in Reference 9. Prompt and fission product gamma rays are emitted with a specific yield of $1.3 \times 10^{13}$ photons/ $(\sec -\mathrm{g})$. The average photon energy is about $0.8 \mathrm{Mev}$. The specific neutron yield is about $2.4 \times 10^{12}$ neutrons/(sec-g) with an average energy of about $2.3 \mathrm{Mev}$.

The Cockcroft-Walton accelerator at Savannah River generates a 1 ma beam current at $150 \mathrm{kev}$. The ${ }^{3} \mathrm{H}(\mathrm{d}, \mathrm{n})$ neutron output of approximately $10^{\mathrm{H}}$ neutrons/sec is nearly isotropic and monoenergetic at $14.7 \mathrm{Mev}$. The photon output is negligible except for a small amount of bremsstrahlung caused by electrons accelerated to the high voltage terminal.

\section{IMAGING PROPERTIES OF FAST NEUTRONS}

Radiographic contrast characteristics of biological specimens can be calculated from published neutron cross sections combined with tissue element content, source spectrum, and detector efficiency as a function of energy. Transport theory must be used for broad beam calculations to include the effects of neutrons that are scattered within the sample but which still reach the detector. If scattering is ignored, an upper limit to the obtainable contrast can be calculated by the narrow beam approximation.

Suppose a small anomalous region of thickness, a, and linear at tenuation coefficient, $\mu_{a}(E)$ is imbedded in a homogeneous specimen of thickness, $x$, and linear attenuation coefficient, $\mu_{\mathrm{x}}(\mathrm{E})$. The contrast between the neutron count in a detector of small but finite size immediately behind the anomaly, $\mathrm{N}_{\mathrm{a}}$, and the count of a similar detector away from the anomaly, $N_{X}$, is defined as ${ }^{10}$

$$
C=\frac{N_{x}-N_{a}}{N_{x}+N_{a}}
$$

If the counts are large enough so that statistical fluctuations can be ignored, the absolute value of the contrast can be expressed as

$|C|=\left|\frac{\int_{0}^{\infty} \Phi_{0}(E) \exp \left(-\mu_{x}(E) x\right)\left\{1-\exp \left[\mu_{x}(E)-\mu_{a}(E)\right] a\right\} \epsilon(E) d E}{\int_{0}^{\infty} \Phi_{0}(E) \exp \left(-\mu_{x}(E) x\right)\left\{1+\exp \left[\mu_{x}(E) \mu_{a}(E)\right] a\right\} \epsilon(E) d E}\right|$

where $\Phi_{O}(E)$ is the fluence (neutrons $/ \mathrm{cm}^{2}$ ) at the detector in the abselte of the specimen and $\epsilon(E)$ is the detector efficiency, both as functions of chergy. If the source is monoenergetic at $E_{S}$, equation 2 reduces to 
$|C|=\left|\frac{1-\exp \left[\mu_{\mathrm{x}}\left(\mathrm{E}_{\mathrm{s}}\right)-\mu_{\mathrm{a}}\left(\mathrm{E}_{\mathrm{s}}\right)\right] \mathrm{a}}{1+\exp \left[\mu_{\mathrm{X}}\left(\mathrm{E}_{\mathrm{s}}\right)-\mu_{\mathrm{a}}\left(\mathrm{E}_{\mathrm{s}}\right)\right] \mathrm{a}}\right|$

If $\left[\mu_{\mathrm{x}}\left(\mathrm{E}_{\mathrm{s}}\right)-\mu_{\mathrm{a}}\left(\mathrm{E}_{\mathrm{s}}\right)\right]$ a is small, equation 3 reduces to

$|C| \cong\left|\frac{1}{2}\left[\mu_{\mathrm{a}}\left(\mathrm{E}_{\mathrm{s}}\right)-\mu_{\mathrm{x}}\left(\mathrm{E}_{\mathrm{s}}\right)\right] \mathrm{a}\right|$

The linear attenuation coefficients of muscle, fat, and bone $\left(\mu_{\mathrm{m}}, \mu_{\mathrm{f}}\right.$, and $\mu_{\mathrm{b}}$, respectively) are shown as functions of energy in Figure $1 .^{*}$ For a ${ }^{3} \mathrm{H}(\mathrm{d}, \mathrm{n})$ accelerator producing 14.7-Mev neutrons, $\mu_{\mathrm{m}}=0.096 \mathrm{~cm}^{-1}, \mu_{\mathrm{f}}=0.097 \mathrm{~cm}^{-1}$, and $\mu_{\mathrm{b}}=0.123 \mathrm{~cm}^{-1}$. Substituting these values into equation 4 shows that muscle and fat will not be distinguishable, but bone will appear as an area of slightly positive contrast (as opposed to thermal neutron radiography, where bone offers negative contrast against soft tissues). Air will have the highest contrast against muscle.

The fission spectrum of a ${ }^{252} \mathrm{Cf}$ source (Figure 1) is broadly distributed about an average energy of $2.3 \mathrm{Mev}^{9}$ for such a broad-spectrum source, the contrast as calculated by equation 2 is not independent of the specimen thickness, $x$. Figure 2 shows absolute values of the contrast of small thicknesses of fat, bone, and air embedded in various thicknesses of muscle. The detector efficiency was assumed to be uniform throughout the energy spectrum, so that for real detectors, small differences from Figure 2 can be anticipated.

For both sources, fat and bone show little contrast against muscle. Air, however, offers a high cuntrast. Consequently, the only value that fast neutron radiography appears to have for clinical diagnosis is the ability to image air pockets in the presence of bone structures that would interfere in X-ray imaging. Lung radiography, pneumoencephalography, and air myelography are examples of clinical procedures that might benefit from the use of fast neutron radiography.

Fast neutron radiographs for the detection of metallic objects in tissue or for the delineation of injected positive contrast agents will show much less contrast than conventional $X$-radiographs. Figure 3 shows the linear attenuation coefficients of the naturally occurring elements for $60-\mathrm{kev} \mathrm{X}$-rays ${ }^{13}$ and for 2.3- and 14-Mev neutrons. ${ }^{12}$ Much greater positive contrast can, in general, be obtained with $\mathrm{X}$-rays because the coefficients are larger by orders of magnitude.

* The element composition of muscle and fat tissues is taken from Reference 11 and that of bone cortex is taken from Reference 3 . The neutron cross sections are taken from Reference 12. 


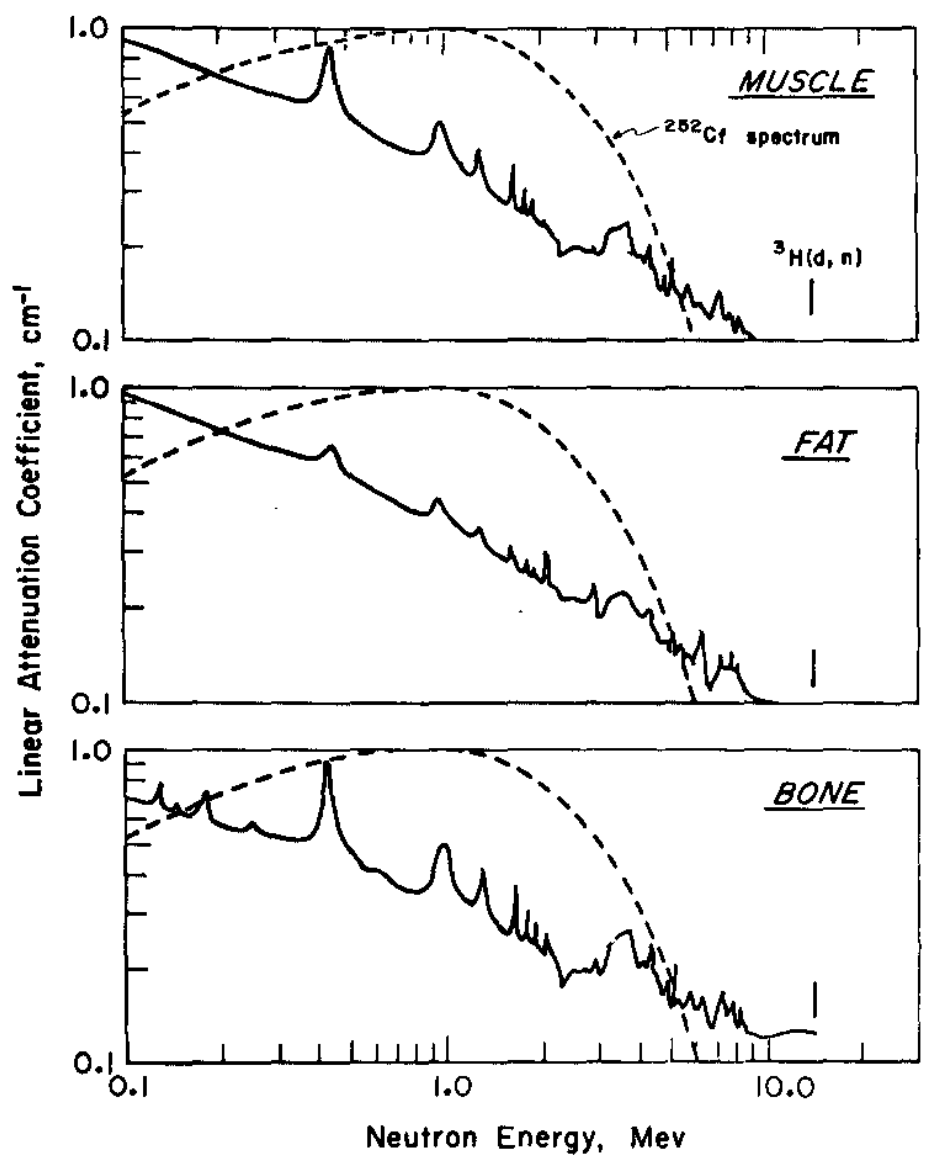

FIG. 1 LINEAR ATTENUATION COEFFICIENTS OF FAST NEUTRONS IN VARIOUS HUMAN TISSUES

All water density tissues are assumed to have coefficients similar to that of muscle. Hydrogen dominates the attenuation, but the fine structure is caused by resonances in carbon and oxygen. 


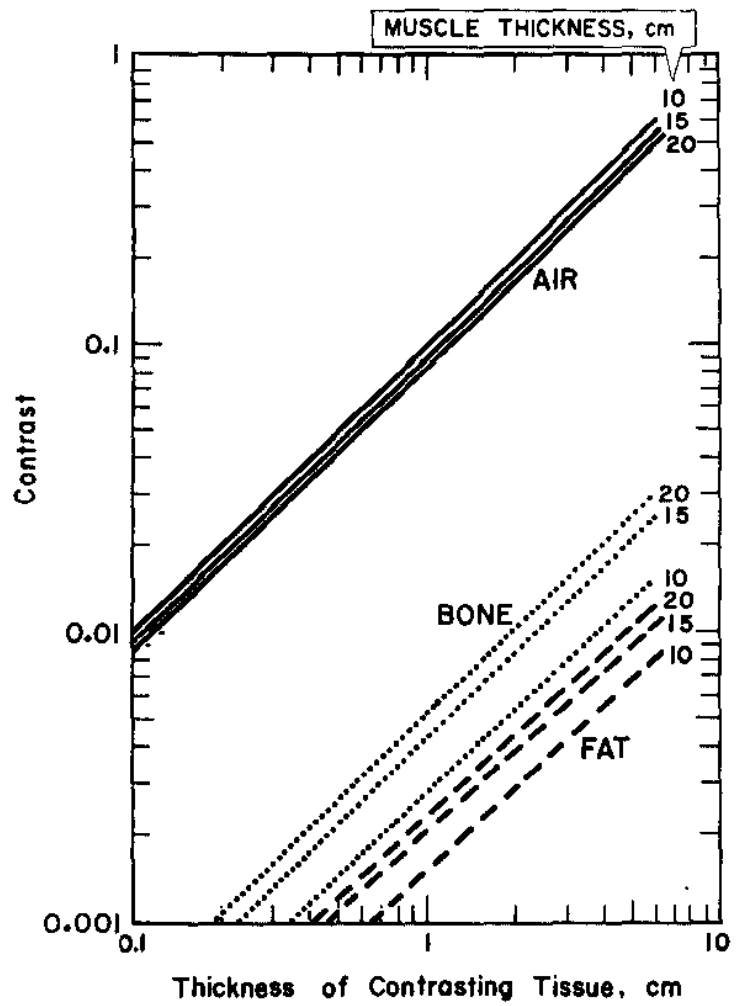

FIG. 2 CONTRAST OF AIR, BONE, AND FAT IN VARIOUS THICKNESSES OF MUSCLE FOR ${ }^{252} \mathrm{Cf}$ SOURCE SPECTRUM

Note that air has large contrast against muscle, but bone and fat are almost indistinguishable from muscle.
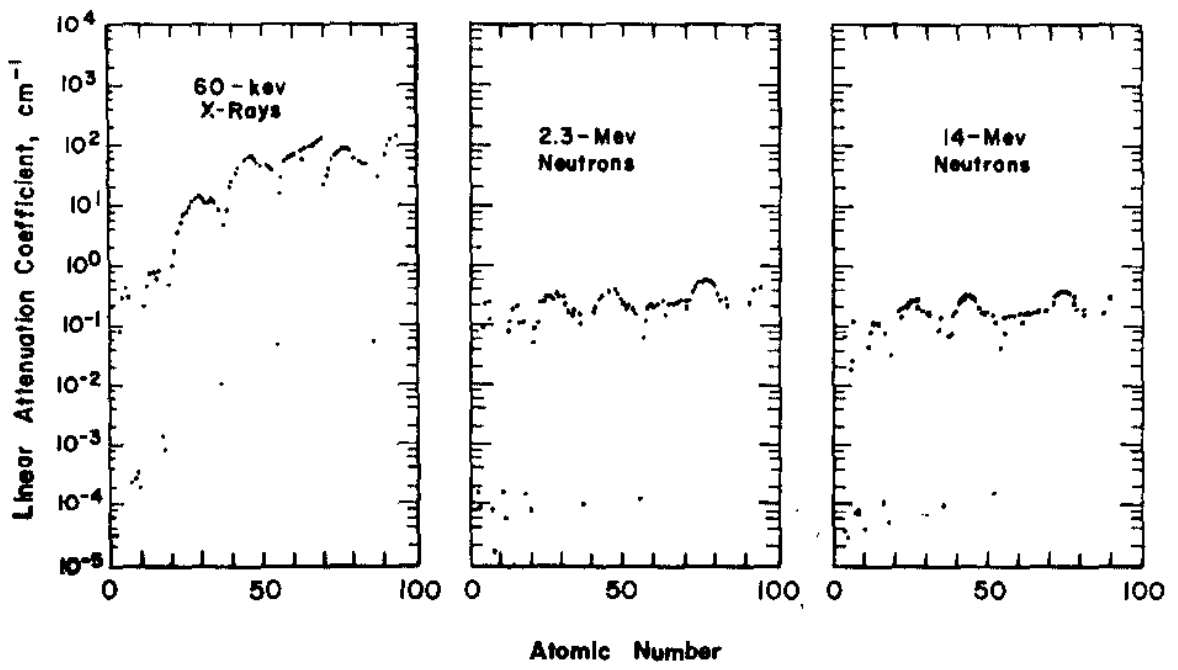

FIG. 3 LINEAR ATTENUATION COEFFICIENTS OF THE ELEMENTS FOR 60-kev X-RAYS AND FOR 2.3- AND 14-Mev NEUTRONS 


\section{CLINICAL CONSTRAINTS ON FAST NEUTRON RADIOGRAPHY}

The clinical interest in fast neutron radiography results from its ability to image air pockets without bone interference. However, the fast neutron exposure must be accomplished within reasonable radiation dose limits and in relatively short exposure times. Some clinical procedures require very high radiation exposures; but, in general, dose levels of five to ten rads within a few seconds exposure time are approximately the limiting conditions that are tolerated for human diagnosis. Any proposed scheme of radiography should be measured against these criteria.

\section{Dose}

Fast neutrons deliver about two orders of magnitude more dose per incident particle than conventional X-rays. The bar chart in Figure 4 compares the dose per unit incident fluence for $60-\mathrm{kev} \mathrm{X}$-rays, for $2.3 \mathrm{-Mev}$ neutrons (the average energy of the ${ }^{252} \mathrm{Cf}$ spectrum), ${ }^{9}$ and for $14.7-\mathrm{Mev}$ neutrons (from ${ }^{3} \mathrm{H}(\mathrm{d}, \mathrm{n})$ accelerators). ${ }^{14.15}$ Thus, incident neutron fluences of approximately $1.3 \times 10^{9}$ neutrons $/ \mathrm{cm}^{2}$ are all that can be delivered to a patient if the dose is to be no more than 10 rads during examination. Whether useful images can be obtained within this dose limitation depends on the attenuation of the neutrons in the patient, the efficiency of neutron detection, and the desired sharpness of the image contrasts.

Presumably, the statistically limiting step in radiography is the detection of image-bearing neutrons. Contrast, as defined by equation 1 , is not statistically significant unless it is equal to or greater than its own standard deviation, $\Delta \mathrm{C}$, by some factor, $\mathrm{k}$ :

$$
\mathrm{C}=\mathrm{k} \Delta \mathrm{C}(\mathrm{k} \geqslant 1)
$$

The absolute minimum detectable contrast is $\Delta \mathrm{C}(\mathrm{k}=1)$.

When $N_{X}$ and $N_{a}$ are independent of each other, it can be shown that ${ }^{16}$

$$
\Delta C \cong\left(\frac{1+C \cdot C^{2}-C^{3}}{2 N_{x}}\right)^{1 / 2}
$$

The minimum number of neutron detections required for a given contrast, $\mathrm{C}$, to be statistically significant by factor $\mathrm{k}$ is thus

$$
N_{x}=k^{2}\left(\frac{1+C-C^{2}-C^{3}}{2 C^{2}}\right)
$$

If $\mathrm{d}^{2}$ is the area of the individual region of the detector in which $\mathrm{N}_{\mathrm{x}}$ neutrons are detected, the dimension $d$ can be considered (somewhat loosely) as the resolution of the image. The recorded direct fluence per unit energy interval is given as 


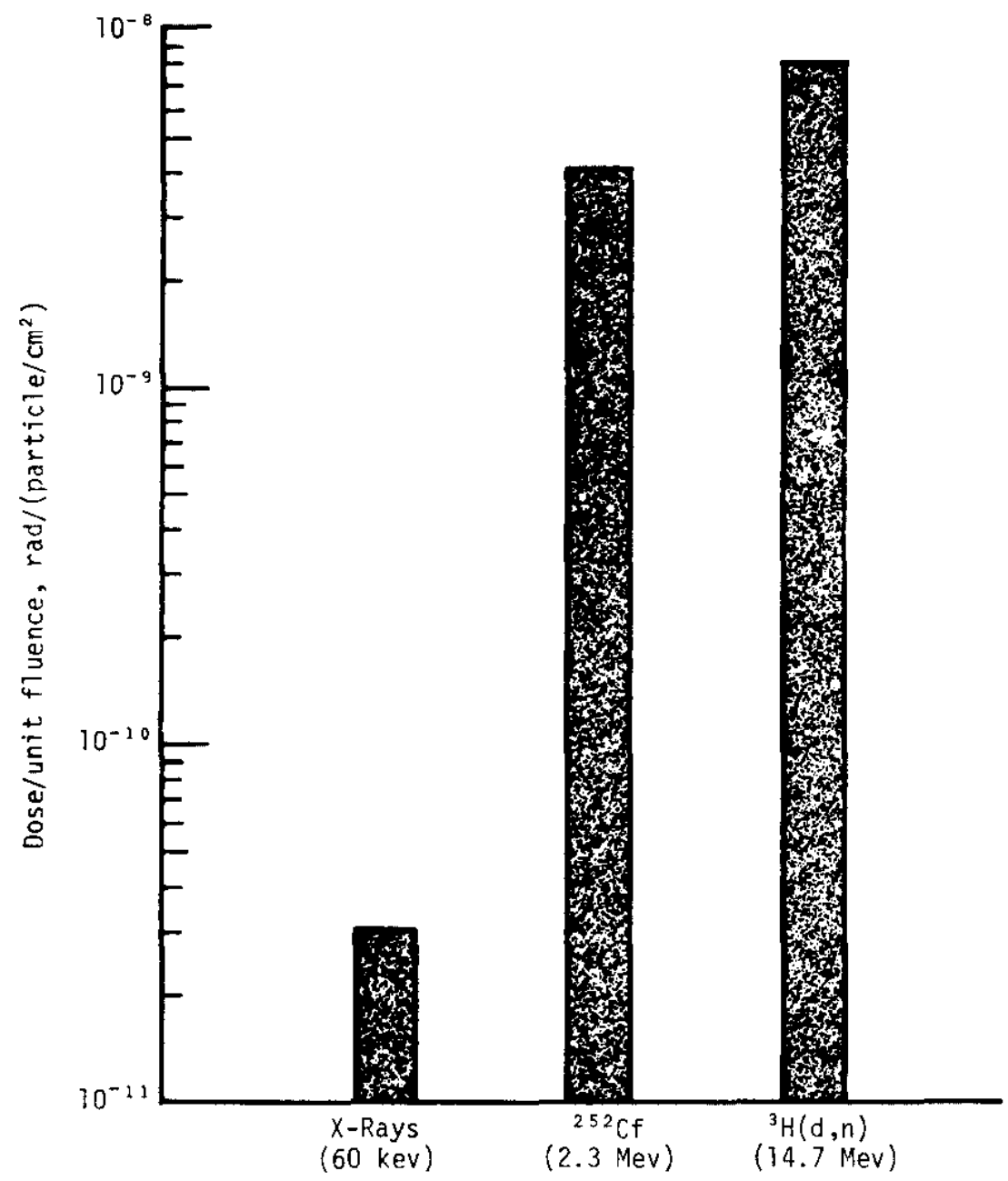

FIG. 4 COMPARISON OF THE DOSE PER UNIT FLUENCE DELIVERED TO THE SURFACE OF 30-cm PHANTOM BY 60-kev X-RAYS, 2.3-Mev NEUTRONS AND 14.7 Mev NEUTRONS

$$
\Phi_{\mathrm{rec}}(E)=\Phi_{\mathrm{o}}(\mathrm{E}) \epsilon(\mathrm{E}) \exp \left[-\mu_{\mathrm{x}}(\mathrm{E}) \mathrm{x}\right]=\mathrm{N}_{\mathrm{x}}(\mathrm{E}) / \mathrm{d}^{2}
$$

where $N_{x}=\int_{0}^{\infty} N_{x}(E) d E$

The presence of scattered neutrons is ignored in this calculation.

The physical dose per unit energy interval, $D_{Z}(E)$, at some point $z$ in a specimen can be estimated in terms of the incident fluence on the specimen per unit energy interval, $\Phi_{i}(E)$ :

$$
D_{z}(E)=F_{z}(E) \Phi_{i}(E)
$$


The function $F_{z}(E)$, in terms of rads/unit fluence, was calculated ${ }^{12}$ by numerical methods for a parallel beam of neutrons incident on a $30-\mathrm{cm}$-thick, homogeneous slab of tissue-equivalent material. Although equation 8 cannot be rigorously applied to divergent beam geometries or to actual patients, it can be used to estimate the approximate dose absorbed during a fast neutron exposure. Thus

$$
D_{z}=\int_{0}^{\infty} F_{z}(E) \Phi_{i}(E) d E \cong \int_{0}^{\infty} F_{z}(E) \Phi_{0}(E) d E
$$

where $\Phi_{0}(E)$ is obtained from the requirements of contrast and resolution as expressed in equations 6 and 7 .

\section{Exposure Time}

The exposure time required for making a radiograph depends on the detection technique used. The fastest method is a broad beam technique where the detector records all of the image simultaneously (conventional $\mathrm{X}$-rays are made in this manner). The minimum required exposure time $(\mathrm{sec})$ in the narrow beam approximation is

$$
\mathrm{T} \cong \frac{\Phi_{0}}{\phi_{0}}
$$

where $\Phi_{0}$ is the required fluence in the absence of the specimen, and $\phi_{\mathrm{O}}$ is the available flux (neutrons $/ \mathrm{cm}^{2}-\mathrm{sec}$ ). For isotropic point sources, $\phi_{\mathrm{O}}$ is given by the inverse square law,

$$
\phi_{\mathrm{o}}=\frac{\mathrm{N}}{4 \pi \mathrm{R}^{2}}
$$

where $\mathrm{N}$ is the source intensity (neutrons/sec) and $\mathrm{R}$ is the distance $(\mathrm{cm})$ between the source and the detector.

Single detector transmission scanning is the slowest mode of radiography. If the area to be scanned is $A$ and the detector cross section is $\mathrm{d}^{2}$, the total time required for the exposure can be approximated by

$$
\mathrm{T} \cong \frac{\mathrm{A}}{\mathrm{nd}^{2}}\left(\begin{array}{l}
\Phi_{\mathrm{o}} \\
\phi_{\mathrm{o}}
\end{array}\right)
$$

if n separate detectors are used. 


\section{GAMMA AND SCATTERED NEUTRON INTERFERENCE}

Most neutron detectors are also sensitive in some degree to $\boldsymbol{\gamma}$-rays. The potential value of fast neutron radiography is its ability to image air pockets without bone interference. However, $\gamma$-rays are attenuated enough in bone to cause an overlying bone display on the neutron image. Therefore, it is desirable to minimize the $\gamma$ sensitivity of the neutron detector.

Gamma rays from the source do not interfere in imaging with ${ }^{3} \mathrm{H}(\mathrm{d}, \mathrm{n})$ accelerators; the small amount of bremsstrahlung is easily screened out. On the other hand, in fast neutron radiography with ${ }^{252} \mathrm{Cf}$ sources $\gamma$-ray interference is significant; the photon source intensity is almost an order of magnitude greater than the neutron source intensity. Another source of $\gamma$-ray background is the ${ }^{1} \mathrm{H}(\mathrm{n}, \gamma)$ reaction producing $2.2-\mathrm{Mev}$ photons. ${ }^{18}$

Image interference can also be anticipated from neutrons scattered within the patient whenever the section being radiographed is thicker than about one neutron mean free path. Unfortunately, there is no mechanical way to prevent these neutrons from reaching a broad beam detector. In slow neutron radiography, anti-scatter grids of alternating layers of absorber and transmitter can be constructed; ${ }^{19}$ but effective grid construction is impossible for fast neutrons because the linear attenuation coefficients of all elements are quite low, usually $<1 \mathrm{~cm}^{-1}$ (Figure 3).

In principle, interference caused by scattered neutrons can be reduced if the detector is separated from the sample. This technique is useful in cases where the scattered neutron divergence from the sample is much greater than the divergence of the unattenuated beam from the source. Thus, as the detector is separated from the sample, the scattered fluence falls more rapidly than the direct fluence.

Neutrons can also be scattered within the detector itself. Because the attenuation cross sections of all materials are low, the detector must be several centimeters thick to obtain a high probability of an interaction. That interaction is most likely to be elastic scattering, and if all dimensions of the detector are much greater than one mean free path, other collisions will probably occur within the detector before the neutron is absorbed or escapes. If the detector records the neutron at each collision, the resolution of the detector is degraded.

\section{EVALUATION OF PROPOSED IMAGING SYSTEMS}

Three different fast neutron imaging systems were investigated in an attempt to find one that would satisfy dose and exposure time requirements, while overcoming imaging difficulties caused by $\boldsymbol{\gamma}$-ray and scattered neutron interference. All these methods use detectors based on the production of recoil protons from neutronhydrogen nucleus collisions. The proton is observed either through direct exposure of photographic film or through secondary ionization and excitation of phosphors.

Detectors based on other fast neutron reactions, such as ( $n, 2 n),(n$, fission), etc., were not considered because their maximum efficiencies are lower than that of the proton recoil method. 


\section{Broad Beam Radiography with ${ }^{3} H(d, n)$ Accelerator}

Direct neutron radiographs were made with 14.7-Mev neutrons from the $150-\mathrm{kv}$ accelerator by exposing various types of X-ray films in a "Radelin T-2"* X-ray cassette (as recommended by Tochilin). ${ }^{18}$ The cassette consists of a $0.32-\mathrm{cm}$ front plastic piece, two $0.05-\mathrm{cm}$ converter screens containing calcium tungstate scintillator plastic binder, and an aluminum backing. The X-ray film, typically $0.02-\mathrm{cm}$ thick, is sandwiched between the two converter screens.

Neutrons were detected through recoil protons that either directly exposed the film or caused scintillations ( $4200 \mathrm{~A}$ ) in the calcium tungstate phosphor. Acrylic plastic sheets of various thicknesses were substituted for the normal front piece to determine the minimum required thickness of the proton source material. For a given exposure, film density increased almost linearly with increasing plastic thickness for thicknesses up to $0.15 \mathrm{~cm}$, beyond which the density was constant. This result is consistent with the average range of recoil protons anticipated from collisions of 14-Mev neutrons with hydrogen nuclei. If the hydrogen content of the film and the converter screen is assumed to be similar to that of the acrylic plastic sheet used as the proton radiator, the first-collision detection efficiency is calculated to be no more than $1 \%$.

An attempt was made to reduce image interference from neutrons scattered within the object by placing the detector cassette at various distances behind the object. Test objects were "Plexiglas"** blocks $(20 \mathrm{~cm}$ by $15 \mathrm{~cm}$ with thicknesses of 5,10 , and $15 \mathrm{~cm}$ ) with $1-$ and $2-\mathrm{cm}$-diameter holes normal to the beam line. Improvement in the images of the voids was negligible even with separations up to $50 \mathrm{~cm}$ beyond a $61-\mathrm{cm}$ source-to-sample distance, probably because of the predominantly forward scattering of 14.7-Mev neutrons and ${ }^{1} \mathrm{H}(\mathrm{n}, \gamma)$ reactions within the samples.

It is possible to construct a broad beam detector efficient enough for $14.7-\mathrm{Mev}$ neutrons to meet the clinical dose requirements. For instance, a detector can be made from a colinear array of long fibers of a plastic scintillator parallel to the the neutron beam. The "fiber scintillator" acts as its own light pipe and prevents the dispersion of light that usually follows scintillation in a thick detector. The minimum spatial resolution of the detector is the diameter of the individual fibers. A detector made from 4-cm lengths of NE-102 plastic scintillator would have an efficiency of approximately $11 \%$. Furthermore, this length should not be large enough to cause significant image smearing from multiple detections.

Three different clinical situations have been assumed as models for evaluation of fast neutron radiography: pneumoencephalography with a required spatial resolution of $0.02 \mathrm{~cm}$, chest radiography with a resolution of $0.1 \mathrm{~cm}$, and air myelography with a resolution of $0.14 \mathrm{~cm}$. These resolutions are typical of the capabilities of conventional roentgenographic and fluoroscopic techniques.

* Registered Trademark of U. S. Radium Corporation

** Registered Trademark of Rohm \& Haas $\mathrm{Co}$. 
For the monoenergetic case with small contrasts, equation 9 yields

$$
D_{z}=\frac{F_{z} k^{2} \exp \left[\mu_{x}\right]}{2 C^{2} d^{2} \epsilon}
$$

This equation was used to calculate the narrow-beam dose from 14.7-Mev neutrons, at one $\mathrm{cm}$ beneath the surface of a given thickness of muscle, that is required to delineate regions of contrast as low as $1 \%(\mathrm{C}=0.01)$. If the detector efficiency is $100 \%(\epsilon=1.0), \mu=0.096 \mathrm{~cm}^{-1}$ for muscle, $\mathrm{k}=1$, and $\mathrm{F}_{\mathrm{z}}=7 \times 10^{-9}$ $\mathrm{rads} /\left(\right.$ neutron $/ \mathrm{cm}^{2}$ ); then equation 12 becomes

$$
\mathrm{D}_{\mathrm{z}}=\frac{3.5 \times 10^{-5} \exp [0.096 \mathrm{x}]}{\mathrm{d}^{2}}
$$

The required doses from equation 13 for the clinical procedures discussed above are shown in Figure 5. Also shown in Figure 5 are the required exposure times for $a^{3} \mathrm{H}(\mathrm{d}, \mathrm{n})$ accelerator with an output of $10^{11}$ neutrons $/ \mathrm{sec}$ at $61 \mathrm{~cm}$ from

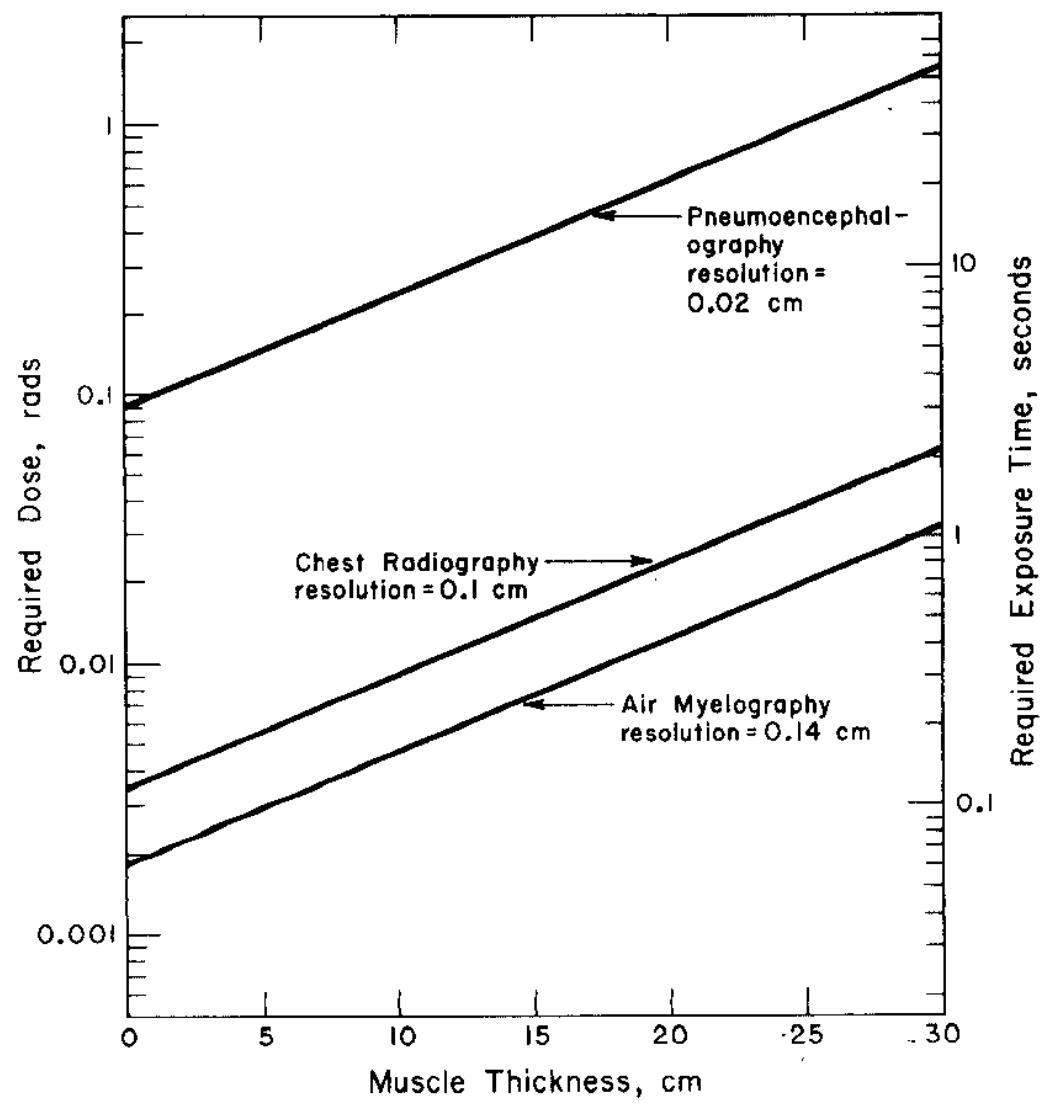

FIG. 5 DOSE AND EXPOSURE TIME FOR IMAGING WITH A ${ }^{3} \mathrm{H}(\mathrm{d}, \mathrm{n})$ ACCELERATOR (10 ${ }^{11}$ NEUTRONS/SEC) AND WITH A $100 \%$ EFFICIENT DETECTOR AT $61 \mathrm{~cm}$ FROM THE SOURCE 
the detector. These results indicate that dose considerations should not restrict the use of fast neutron radiography with the ${ }^{3} \mathrm{H}(\mathrm{d}, \mathrm{n})$ accelerator. For instance, if the $11 \%$ efficient fiber scintillator system were used to make a pneumoencephalograph (the human head is about $15 \mathrm{~cm}$ thick), a dose of only 3.4 rads would be absorbed. However, the required $120 \mathrm{sec}$ exposure is very long for clinical situations. A radiograph of the lung (about $12 \mathrm{~cm}$ of equivalent muscle thickness) would requixe a 10 second exposure, which is about an order of magnitude longer than desirable to keep motion unsharpness small.

Figure 6 compares three radiographs of a dog's chest -... a $60-\mathrm{KVP}$ X-radiograph, a 2-Mev $\mathrm{X}$-radiograph, and a 14-Mev neutron radiograph taken with the cassette method. The contrast and definition of the neutron radiograph have been compromised by the geometric unsharpness caused by the finite focal spot $(1 \mathrm{~cm}$ at $61 \mathrm{~cm}$ source-to-detector distance), and probably by scattered neutrons and capture gammas. There is yet no convincing evidence that, even with strong focusing, such radiographs would have sufficient advantage over megavoltage X-ray techniques to warrant the development of the necessary detectors. Because the attenuation coefficients of tissue are uniformly low, 14.7 Mev radiography is too insensitive for clinical use.

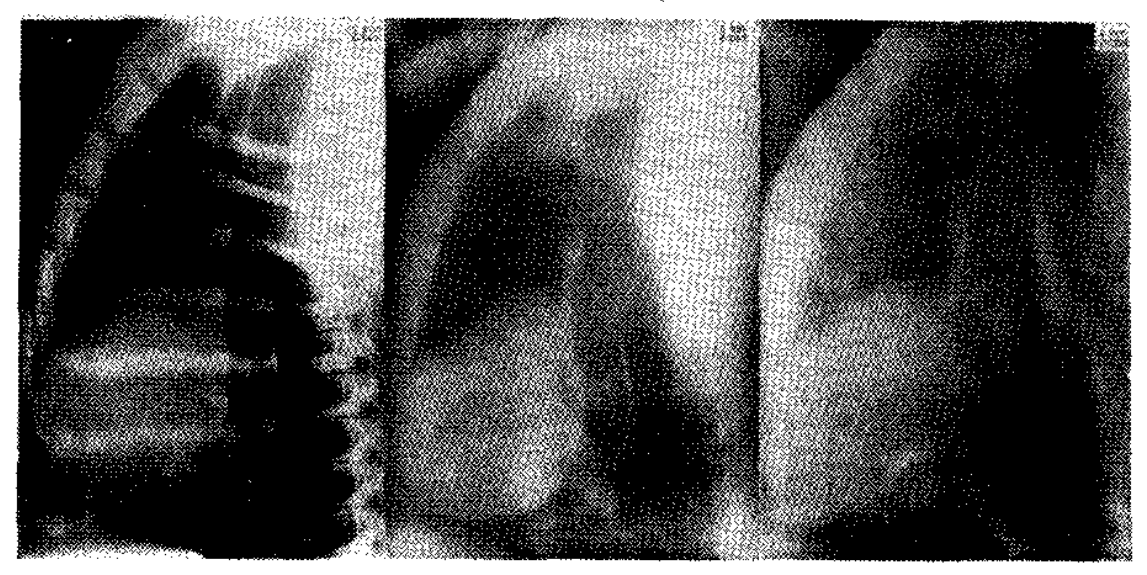

\section{FIG. 6 COMPARISON OF 60-KVP X-RAY, 2-Mev X-RAY, AND 14.7-Mev NEUTRON RADIOGRAPH OF DOG'S CHEST (LATERAL EXPOSURE)}

\section{Broad Beam Radiography with ${ }^{252} \mathrm{Cf}$ Sources}

The high $\gamma$ yield of $252 \mathrm{Cf}$ makes the simple plastic scintillator detector, described in the previous section, impractical. G.T. Reynolds has suggested ${ }^{20}$ an imaging system that would minimize ${ }^{252} \mathrm{Cf} \gamma$ interference in broad beam neutron radiography. Fast neutrons would be detected by a mixture of nonscintillating plastic that serves as a proton radiator and phosphors that scintillate when struck by the recoil protons. The widely used Hornyak button, $\mathrm{ZnS}(\mathrm{Ag})$ 
in a plastic matrix, is a detector of this type. The light signals would be amplified in a conventional image intensifier and recorded from a television display system. The image orthicon of the display system has a blanking circuit to reject light signals from the intensifier below some predetermined threshold. Because signals from $\gamma$ interactions would be much smaller than those from neutronproton collisions, discrimination against gamma interference would be possible.

The required doses for ${ }^{252} \mathrm{Cf}$ fast neutron radiography can be estimated with equation 11 where $\mu=0.19 \mathrm{~cm}^{-1}$ and $F_{z}=4 \times 10^{-9}$ rads $/\left(\right.$ neutron $/ \mathrm{cm}^{2}$ ). In this calculation, the ${ }^{252} \mathrm{Cf}$ neutrons were assumed monoenergetic at $2.3 \mathrm{Mev}$, the average energy of the spontaneous fission spectrum. The error resulting from the monoenergetic approximation is small. Calculations have been made for the same three clinical procedures described for 14.7-Mev broad beam radiography. Figure 7 shows the approximate required doses for imaging contrasts as small as $1 \%(\mathrm{C}=0.01, \mathrm{k}=1)$, assuming a $100 \%$ efficient detector $(\epsilon=1.0)$.

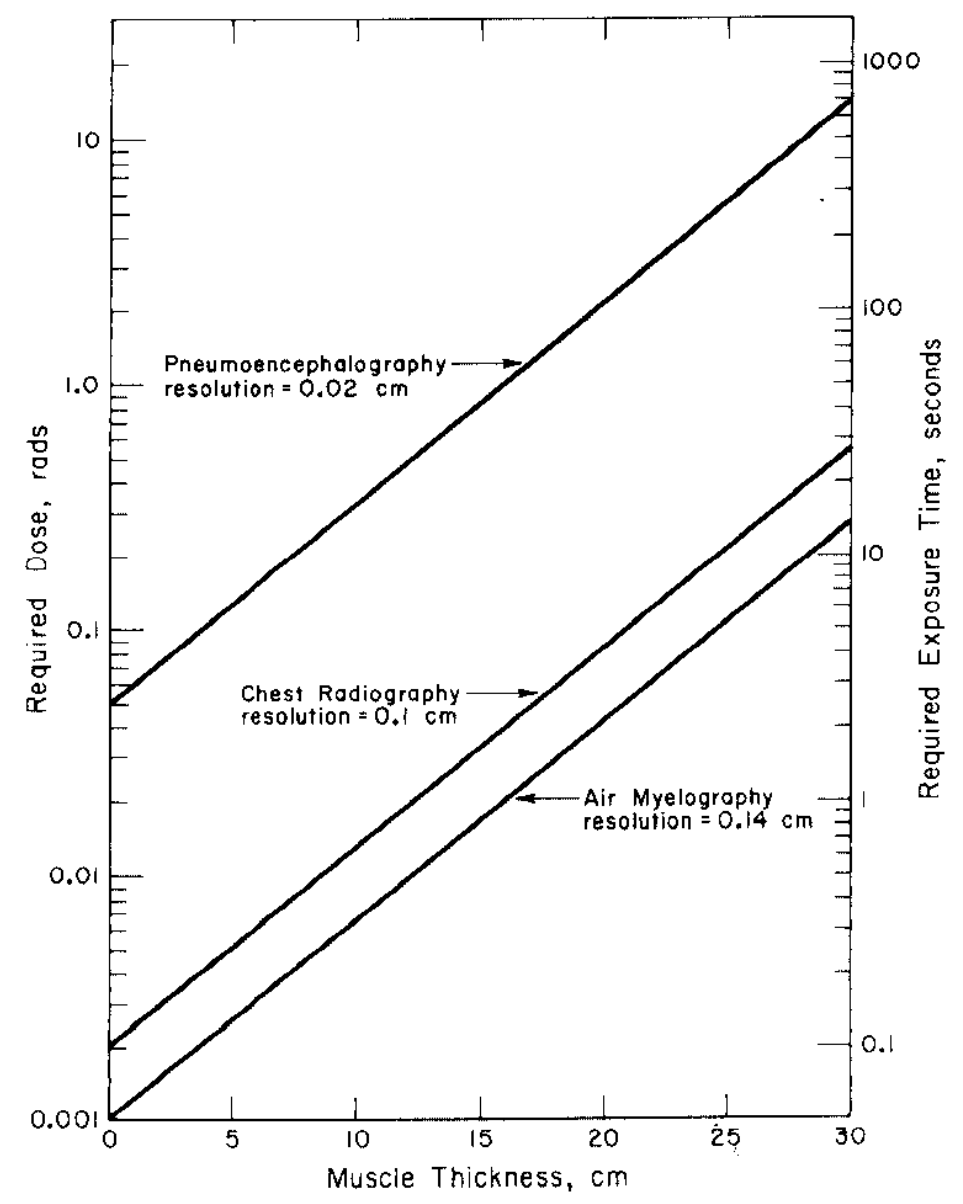

FIG. 7 REQUIRED DOSE AND EXPOSURE TIME FOR BROAD BEAM IMAGING WITH A $100 \%$ EFFICIENT DETECTOR AT $61 \mathrm{~cm}$ FROM A $100-m g{ }^{252} \mathrm{C} f$ SOURCE 
Exposure times, also shown in Figure 7, were calculated assuming a 100-mg ${ }^{252} \mathrm{Cf}$ source (about the largest practical amount) at $61 \mathrm{~cm}$ from the detector (the minimum practical separation for adequate shielding). The exposure time is too long for pneumoencephalography, even if the detector were $100 \%$ efficient. However, the less stringent resolution requirement for chest radiography reduces the exposure sufficiently to warrant consideration of a specific detector design.

Consider first the $\boldsymbol{\gamma}$-ray discrimination requirement. In the average adult, the lungs are equivalent in neutron attenuation to approximately $12 \mathrm{~cm}$ of muscle tissue and the neutron transmission is about 0.10 . The ${ }^{252} \mathrm{Cf} \gamma$ spectrum transmission is considerably higher, about 0.38 . If the detected $\gamma$-rays that pass through the lung are to be held to $\leqslant 10 \%$ of the detected neutrons, the efficiency of neutron detection should be at least 200 times greater than the efficiency for $\gamma$-ray detection.

A simple neutron detector with $\gamma$-ray discrimination capabilities consists of small phosphor grains uniformly dispersed in a plastic medium. If the size of the phosphor grains is no larger than the average range of recoil protons from the elastic scattering of neutrons with protons, then "the recoil proton. . . can lose most of its energy in a phosphor grain, producing a large light pulse. Secondary electrons from gamma rays, however, lose less energy in a phosphor grain (because of smaller energy loss per unit path) and therefore produce smaller light pulses." 21 This method of discrimination limits the maximum efficiency for recoil proton detection because most protons will never enter a grain at all. However, the electronic biasing can be performed in the image orthicon.

A transparent detector can be made from the mixture only if the indices of refraction of the phosphor grains and the plastic medium are closely matched. Brown and Hooper ${ }^{21}$ have discussed detectors made of $\mathrm{KI}(\mathrm{Tl})(\eta \cong=1.69)$ and polystyrene $(\eta \cong 1.6)$, and of "Scintillon"* $(\eta \cong 1.6)$ and polystyrene. These detectors ( $5 / 8$ inch diameter by $5 / 8$ inch height) were described as being nearly transparent.

The simplest detector would be a thick slab; however, the image from a thick detector would be destroyed by light dispersion unless a large optical lens were used to focus the image onto the input of the image intensifier. The light output may be more efficiently conserved if the detector is made from an array of scintillating filaments, each an internally reflecting light pipe whose diameter is less than or equal to the desired resolution. Polystyrene-phosphor mixtures can be extruded and coated with a reflector to form optically decoupled filaments. The array would be aligned with the filaments parallel to the neutron beam, and appropriate fiber optics would transfer the light signals to the image intensifier.

The efficiencies were measured by Brown and Hooper, ${ }^{21}$ of $5 / 8$-inch-1hick "Scintillon" -polystyrene and KI(T) )-polystyrene mixtures for neutron and $\gamma$-raty detection. Two different neutron sources were used, a polonium-beryllium source and a nearly monoenergetic source at $2.5 \mathrm{Mev}$ from the ${ }^{2} \mathrm{H}(\mathrm{d}, \mathrm{n}){ }^{3} \mathrm{He}$ reaction. The $\gamma$-ray spectrum of radium was used to test the $\gamma$ efficiency.

* Registered Trademark of National Radiac, Inc., Newark, N. J., for an organic plastic scintillator 
On the basis of these data, a neutron-to-gamma efficiency ratio of 200 , necessary for lung radiography, would limit the attainable neutron efficiency to no more than:

$\begin{array}{lll} & \text { Po-Be } & 2.5 \mathrm{Mev} \\ \text { KI(T1) - polystyrene } & 0.9 \% & <0.2 \% \\ \text { "Scintillon"- polystyrene } & 0.7 \% & <0.02 \%\end{array}$

If the mediastinum were radiographed, a neutron-to-gamma efficiency ratio of 250 to 1 would be required, and the maximum attainable neutron efficiencies would be:

$\begin{array}{lll} & \text { Po-Be } & 2.5 \mathrm{Mev} \\ \mathrm{KI}(\mathrm{Tl}) \text { - polystyrene } & 0.8 \% & <0.2 \% \\ \text { "Scintillon"- polystyrene } & 0.6 \% & <0.02 \%\end{array}$

The ${ }^{252} \mathrm{Cf}$ neutron spectrum, hardened by passage through the lung or medias. tinum, has an average energy close to that of $\mathrm{Po}-\mathrm{Be}$, and the hardened gamma spectrum average closely matches the radium spectrum average. It is estimated that if the length of the fibers were increased to one neutron mean free path (approximately $5.6 \mathrm{~cm}$ ), the neutron efficiencies would be raised to $1.8 \%$ at 200 to 1 and $1.5 \%$ at 250 to 1 . Presumably, filaments longer than one mean free path would be undesirable because multiple scattering would begin to interfere with the image.

These efficiencies are not high enough for further consideration of this method of fast neutron radiography. Figure 7 shows that lungs could be radiographed with a dose of approximately $1 \mathrm{rad}$. However, the exposure time would be about 50 seconds, too long for practical clinical use. To make the system practical, either the cost of ${ }^{252} \mathrm{Cf}$ would have to be significantly less than currently projected, ${ }^{22}$ or a detector with markedly improved efficiency would have to be devised.

An cvaluation of the industrial potential of this system (e.g., the detection of voids in thick metallic objects) was beyond the scope of this study.

\section{Transmission Scanning with $252 \mathrm{Cf}$ Sources}

Transmission scanning has three advantages that have prompted investigation of its suitability for clinical purposes: (1) most scattered neutrons from the specimen can be effectively prevented from reaching the detector system; (2) the counting rate of neutrons in any individual detector is generally small enough so that conventional electronic techniques (e.g., pulse shape discrimination) can be employed to discriminate against $\gamma$ rays with little loss of neutron signal; and (3) multiple detections are minimized so that detectors can be long-in the direction of the primary beam and thus highly efficient.

A schematic design for a transmission scanning system is shown in Figure 10. The system would employ many separate neutron detectors of small cross section arrayed like a picket fence in a single plane. ${ }^{23}$ The neutron emission 

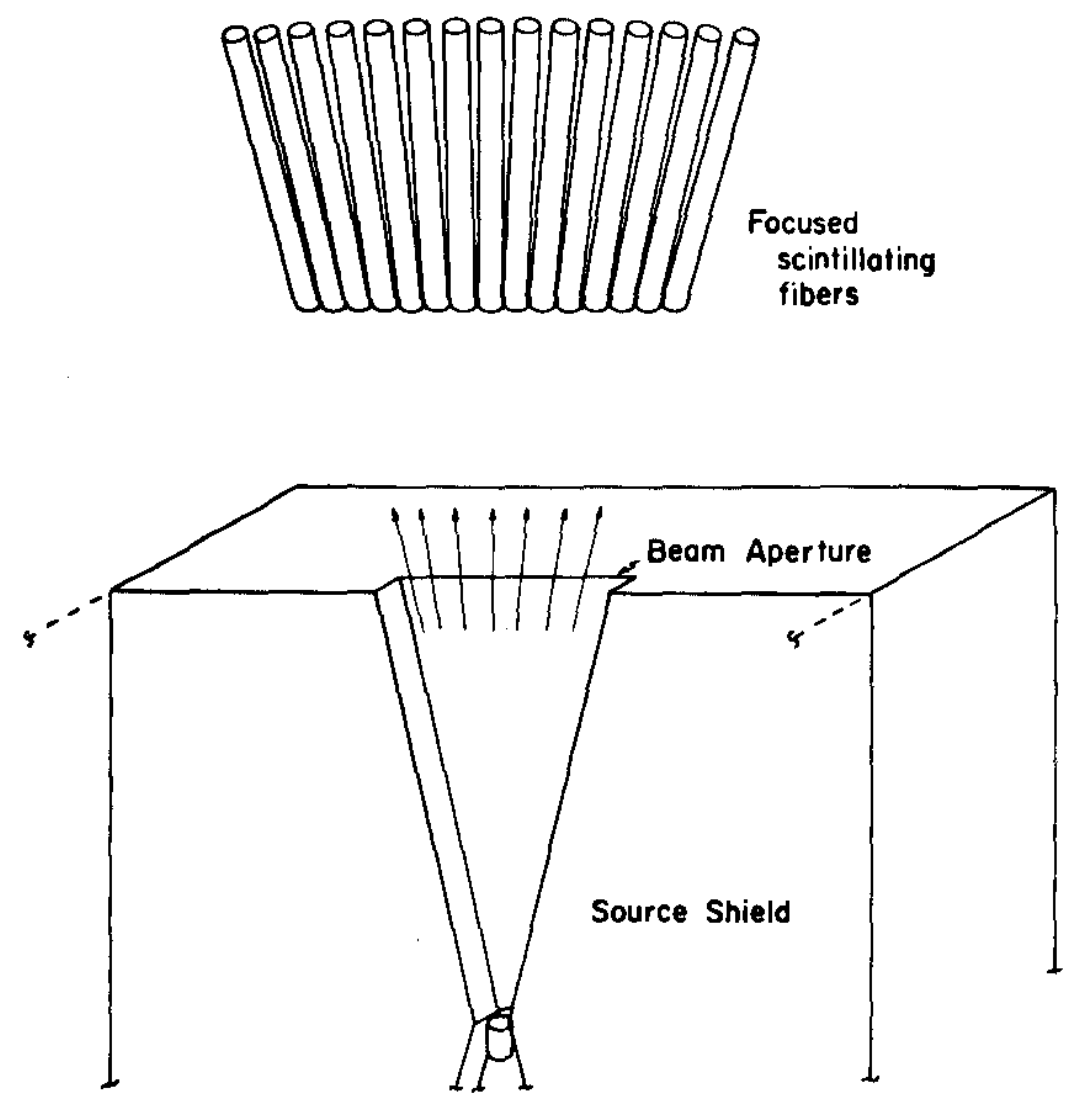

FIG. 8 LINE TRANSMISSION SCANNING FACILITY WITH COLINEAR ARRAY OF SCINTILLATING FIBERS

from the ${ }^{252} \mathrm{Cf}$ source would be collimated by appropriate shielding into a narrow beam of such a length and width as to allow the beam to diverge to the full length and width of the line of neutron detectors. A two dimensional image would be formed by scanning the object to be radiographed between the collimator and the detectors.

If the neutron efficiency of the detector material is known, the required dose for an exposure can be found directly from Figure 7. However, the required exposure times of Figure 7 must be multiplied by $A / \mathrm{nd}^{2}$, where $\mathrm{A}$ is the area swept over in the transmission scan, $n$ is the number of detectors, and $\mathrm{d}^{2}$ is the cross section of each detector. Table II lists required values of these parameters for pneumoencephalography, chest radiography, and air myelography.

Because of the excessive exposure time required, transmission scanning with ${ }^{252} \mathrm{Cf}$ sources has no clinical use for any of the above studies. For example, even if the detectors were $100 \%$ efficient, lung radiography $(12 \mathrm{~cm}$ of muscle) would require approximately 340 seconds, and radiography of the mediastinum $(20 \mathrm{~cm}$ of muscle) would require approximately 1500 seconds. 
TABLE II

DESIGN DATA FOR TRANSMISSION SCANNING

\begin{tabular}{lcccc} 
Cinical Study & $\begin{array}{c}\text { Required Spatial } \\
\text { Resolution }(d)\end{array}$ & $\begin{array}{c}\text { Area to be } \\
\text { Scanned }(A)\end{array}$ & $\begin{array}{c}\text { No. of } \\
\text { Detectors }(n)\end{array}$ & $\begin{array}{c}\text { Time Multiplication } \\
\text { Factor }\left(\text { Affid }{ }^{2}\right)\end{array}$ \\
\cline { 5 - 6 } Pneumoencephalography & $0.02 \mathrm{~cm}$ & $13 \mathrm{~cm} \times 18 \mathrm{~cm}$ & 650 & 900 \\
Chest Radiography & $0.1 \mathrm{~cm}$ & $36 \mathrm{~cm} \times 36 \mathrm{~cm}$ & 360 & 360 \\
Air-Myelography & $0.14 \mathrm{~cm}$ & $5 \mathrm{~cm} \times 36 \mathrm{~cm}$ & 36 & 257
\end{tabular}




\section{ACKNOWLEDGEMENTS}

The authors are indebted to N. P. Baumann of the Savannah River Laboratory for many helpful discussions in the course of this work.

R. C. Cunningham and W. N. Willcox of the Medical College of Georgia took most of the radiographs and made the subsequent densitometer analyses. 


\section{REFERENCES}

1. H. Berger. Neutron Radiography. Elsevier Publishing Co., New York (1965).

2. H. L. Atkins. "Biological Application of Neutron Radiography." Materials Evaluation 23, 453 (1965).

3. 3. P. Barton. "Some Possibilities of Neutron Radiography." Phys. Med. Biol. 9, 33 (1964).

4. J. P. Barton. "State of the Art-Review, Neutron Radiography-Biological Aspects." Neutron Radiography Newsletter No. 1, 11 (1967).

5. M. Brown and P. B. Parks. "Neutron Radiography in Biological Media-Techniques, Observations, and Implications". Am. J. Roent. 163, 254 (1969).

6. M. Brown, J. J. Allen, and P. B. Parks. "Slow Neutron Imaging of Fatty Tissues Through Deuteration with Heavy Water." Biomedical Sciences Instrumentation, Vol. 6, Imagery in Medicine. F. D. Thomas and E. E. Sellers, eds. p 98, Instrument Society of America, Pittsburgh, Pa. (1969).

7. P. B. Parks, S. M. Reichard, and M. Brown. Deuteration in Slow Neutron Radiography of Biological Media. USAEC Report DP-1229, E. I. du Pont de Nemours \& Co., Savannah River Laboratory, Aiken, S. C. (1970).

8. W. C. Reinig. "Advantages and Applications of ${ }^{252} \mathrm{Cf}$ as a Neutron Source." Nucl. Appl. 5, 24 (1968).

9. D. H. Stoddard. Radiation Properties of Californium-252. USAEC Report DP-986, E. 1. du Pont de Nemours \& Co., Savannah River Laboratory, Aiken, S. C. (1965).

10. H. Schober. "The Influence of Shannon's Information Theory on Definition and Measurement of Image Quality." Chapter 16 in The Reduction of Patient Dose by Diagnostic Radiologic Instrumentation. R. D. Mosely and J. H. Rust, eds. p 237, C. C. Thomas, Springfield, Ill. (1969).

11. M. M. Ter-Pogossian. The Physical Aspects of Diagnostic Radiology. Harper and Row, New York (1967).

12. M. D. Goldberg, S. F. Mughabghab, S. N. Purohit, B. A. Magurno, and V. A. May. Neutron Cross Sections, Suppl. No. 2, 2nd ed, Vol 1 and 2, USAEC Report BNL-325, Brookhaven National Laboratory, Upton, N. Y. (1966).

13. E. Storm and H. I. Israel. Photon Cross Sections from 0.001 to $100 \mathrm{Mev}$ for Elements 1 through 100. USAEC Report LA-3253, Los Alamos Scientific Laboratory, Los Alamos, New Mexico (1967).

14. H. E. Johns. The Physics of Radiology. 2nd ed. p 694, C. C. Thomas, Springfield, Ill. (1961).

15. Protection Against Neutron Radiation up to 30 Million Electron Volts, Handbook 63, National Bureau of Standards, U. S. Government Printing Office, Washington, D. C. (1957).

16. W. H. Wilkie, Georgia Institute of Technology, private communication (1968)

17. R. H. Morgan. "The Frequency Response Function." Am. J. Roent. 88, 125 (1962). 
18. E. Tochillin. "Photographic Detection of Fast Neutrons: Application to Neutron Radiography." Phys. Med. Biol. 10, 477 (1965).

19. P. B. Parks and M. Brown. “Antiscatter Grids for Low-Energy Neutron Radiography." Radiol. 92, 178 (1969).

20. G. T. Reynolds, Princeton University, private communication (1969).

21. B. Brown and E. B. Hooper, Jr. "Plastic Phosphor Matrix for Fast-Neutron Detection." Nucleonics 16 (4), 96 (1958).

22. Califormium-252 Progress, Number 4. USAEC, Savannah River Operations Office, Aiken, S. C. (August 1970).

23. P. B. Parks, M. Brown, and D. S. Harmer. "Problems of Fast Neutron Radiography." Biomedical Sciences Instrumentation, Vol.6, Imagery in Medicine: F. D Thomas and E. E. Sellers, eds. p 118, Instrument Society of America, Pittsburgh, Pa. (1969).

TL:jh 